\title{
Pengenalan Sport Masage Pada Masyarakat Melalui Aksi Sosial Upaya Semarak Dies Natalis Universitas Negeri Padang Yang Ke 64
}

\author{
${ }^{1}$ Rosmaneli, ${ }^{2}$ Darni \\ ${ }^{12}$ Jurusan Pendidikan Olahraga, Program Studi Pendidikan Jasmani Kesehatan dan Rekreasi, \\ Fakultas Ilmu Keolahragaan, Universitas Negeri Padang \\ Email: rosmanelimpd@ fik.unp.ac.id ${ }^{1}$, darni_PO@ fik.unp.ac.id ${ }^{2}$ \\ Diterima: 13 Mei 2020; Revisi: 31 Mei 2020; Disetujui: 31 Mei 2020
}

\begin{abstract}
Abstrak
Sport Massage merupakan salah satu relaksi yang alami untuk menyegarkan tubuh baik dari anak-anak, remaja, maupun dewasa. Banyak dari kalangan masyarakat yang belum tau apa itu sport massage. Pada dies natalis ke 64 ini jurusan permasing-masing fakultas menampilkan karya sesuai dengan kelebihan yang dimiliki dengan memperagakan pada stan yang disediakan oleh Universitas Negeri Padang. Salah satunya Fakultas Ilmu Keolahragaan, Jurusan Pendidikan Olahraga yang mengembangkan salah satu potensinya yakni sport massage.Metode pelaksanaan dalam kegiatan pengabdian masyarakat ini metode partisipasif. Menurut pendapat Meaga partisipasif ini merupakan pendekatan yang melibatkan seluruh masyarakat dalam pemetaan dan pemecahan masalah. Fokus pengabdian ini adalah memperkenalkan sport massage dan aksi sosial yang akan membantu tsunami di Palu, hasil dana aksi akan langsung disumbangkan. Sport massage memiliki keuntungan yang banyak bagi kesehatan apalagi bagi tubuh yang selesai melakukan olahraga, apalagi ini akan bisa menjadi salah satu icon kelebihan yang bisa dibanggakan. Solusi dari kegiatan pengabdian kepada masyarakat ini adalah dengan mencukupi kebutuhan sarana dan prasanaa yang bisa meningkatkan nilai ketertarikan orang menggunakan jasa masseur FIK Universitas Negeri Padang serta memberikan pelatihan khusus untuk para tim massage agar bisa memiliki kemampuan yang lebih lagi. Adapun sarana prasana untuk mendukung massage adalah ruangan serta alat-alat yang perlu diperbaharui agar bisa sesuai dengan standar yang ada.
\end{abstract}

Kata Kunci: Sport Massage, Aksi Sosial

\begin{abstract}
Sport Massage is one of the natural relaxants to refresh the body both from children, adolescents, and adults. Many of the people who do not know what sports massage is. At the 64th anniversary anniversary, the department of each faculty was displaying works in accordance with their strengths by displaying a booth provided by Padang State University. One of them is the Faculty of Sport Science, the Department of Physical Education which develops one of its potential namely sports massage. The method of implementation in community service activities is participatory. In Meaga's opinion, this participatory approach is an approach that involves the whole community in mapping and problem solving. The focus of this dedication is to introduce sports massages and social actions that will help the tsunami in Palu, the proceeds of the action funds will be directly donated.Sport massage has many benefits for health especially for the body that has finished exercising, moreover this will be one of the advantages icons to be proud of. The solution of community service activities is to meet the need for facilities and infrastructure that can increase the value of people's interest in using the services of Padang State University FIK masseur as well as providing special training for massage teams in order to have more capabilities. The infrastructure for supporting massage is the room and tools that need to be updated to be in accordance with existing standards.
\end{abstract}

Keywords: Sports Massage, Social Action 


\section{ANALISIS SITUASI}

Universitas Negeri Padang merupakan salah satu perguruan tinggi yang berada dikota Padang, tepatnya pada 23 Oktober 1954- 23 Oktober 2018 berusia 64 tahun. Dipimpin oleh bapak Prof. Ganefri, Ph.D. (Wikipedia). Pada saat pelaksanaan dies natalis dilaksanakan di kampus utama yang terletak di Jln. Prof. Dr. Hamka, Air Tawar, Kota Padang. Dipusatkan di Gedung Auditorium Universitas Negeri Padang yang melibatkan para civitas, mahasiswa dan staf.

Pada dies natalis ke 64 ini jurusan permasing-masing fakultas menampilkan karya sesuai dengan kelebihan yang dimiliki dengan memperagakan pada stan yang disediakan oleh Universitas Negeri Padang. Salah satunya Fakultas IIlmu Keolahragaan, Jurusan Pendidikan Olahraga yang mengembangkan salah satu potensinya yakni sport massage. Yang masih belum banyak diketahui oleh masyarakat terutama lingkungan Universitas Negeri Padang.

Sport massage sangat menguntungkan bagi kesehatan, sehingga pada saat dies natalis Universitas Negeri Padang ke 64 Jurusan Pendidikan Olahraga menurunkan tim massage untuk menyemarakkan dalam rangka aksi sumbang sosial di kota Palu yang membutuhkan ulur tangan kita sebagai makhluk sosial. Dalam aksi sosial ini menurunkan tim massage FIK Universitas Negeri Padang terdiri dari masseur putra dan putri.

Lokasi untuk menyediakan layanan sport massage senidiri sudah disediakan pihak panitia dari penyelenggara dies natalis Universitas Negeri Padang sebagai sarana penunjang yang akan mendukung jalannya pelayanan yang diberikan oleh tim massage. Dengan adanya lokasi khusus untuk giat akan lebih memudahkan masyarakat yang dituju utama adalah mahasiswa dan civitas kampus, sehingga bisa memudahkan sosialiasi dan meminta ulur tangan dari setiap yang ikut berpartisipasi. Diharapkan setiap orang yang ikut serta bisa mendapatkan ilmu pengetahuan serta manfaat dari sport massage dan melalui giat ini bisa sebagai perantara untuk membantu korban tsunami di kota Palu.

\section{SOLUSI DAN TARGET}

Adapun solusi dan target dari pengabdian pada dies natalis Universitas Negeri Padang ke 64 yakni, melalui pelayanan sport massage memiliki peluang yang bisa dikembangkan dengan bantuan kerjasama pihak setempat, tetapi dengan kurangnya sarana dan prasarana serta tim massage generasi selanjutnya sport massage. Sport massage memiliki keuntungan yang banyak bagi kesehatan apalagi bagi tubuh yang selesai melakukan olahraga, apalagi ini akan bisa menjadi salah satu icon kelebihan yang bisa dibanggakan. Solusi dari kegiatan pengabdian kepada masyarakat ini adalah dengan mencukupi kebutuhan sarana dan prasanaa yang bisa 


\section{Journal Berkarya}

Pengabdian kepada Masyarakat Vol. 2, No. 1, Mei, 2020, E- ISSN $\underline{\underline{2686-6218}}$

meningkatkan nilai ketertarikan orang menggunakan jasa masseur FIK Universitas Negeri Padang serta memberikan pelatihan khusus untuk para tim massage agar bisa memiliki kemampuan yang lebih lagi. Adapun sarana prasana untuk mendukaung massage adalah ruangan serta alat-alat yang perlu diperbaharui agar bisa sesuai dengan standar yang ada.

Target luaran dari kegiatan pengabdian ini bisa menjadi tulisan dalam bentuk jurnal yang dipublikasi secara online. Sehingga bisa bermanfaat menjadi bahan rujukan yang akan dipakai untuk yang membutuhkan

\section{METODE PELAKSANAAN}

Metode pelaksanaan dalam kegiatan pengabdian masyarakat ini metode partisipasif. Menurut pendapat Meaga partisipasif ini merupakan pendekatan yang melibatkan seluruh masyarakat dalam pemetaan dan pemecahan masalah. Pada dies natalis Universitas Negeri Padang ini akan melibatakan seluruh yang terlibat di kegiatan ini terutama mahasiswa dan civitas lingkungan Universitas Negeri Padang selama kegiatan berlangsung.

Fokus pengabdian ini adalah memperkenalkan sport massage dan aksi sosial yang akan membantu tsunami di Palu, hasil dana aksi akan langsung disumbangkan. Terdapat tahapan yang dilakukan dalam pengabdian ini, yakni tahapan diskusi atau musyawarah bagaimana jalannya program ini selama dies natalis, perlengkapan yang dibutuhkan. Hal diperkuat menurut pendapat (Asnaldi \& Kibadra, 2019) "Musyawarah disini yaitu tentang Program Pelatihan yang akan dilaksanakan serta kendala-kendala yang dimungkinkan timbul dalam pelaksanaan program ini, sehingga dalam musyawarah ini bisa mendapatkan solusi akan kendala tersebut".

Kemudian dilakukan observasi ditempat dies natalis untuk stan massage. Setelah semua persiapan, tim massage dengan bantuan dosen pembimbing melakukan konsep denah kegiatan untuk kegiatan dies natalis serta menghitung banyak barang yang dibutuhkan selama kegiatan berlangsung. Penguatan dari kegiatan ini dengan menggunakan kerjasama antara mahasiswa dengan dosen untuk kegiatan yang direncanakan dan disepakati sesuai dengan tujuan kegiatan. Kegiatan dilakukan dalam 4 hari dengan tim massage putra dan putri.

\section{PELAKSANAAN KEGIATAN}

Lokasi kegiatan dies natalis Universitas negeri Padang ke 64 ini dilaksanakan di Auditorium, kampus utama dari Universitas Negeri Padang. Dengan melibatkan 8 fakultas yakni, Fakultas Ilmu Pendidikan, Fakultas Bahasa dan Seni, Fakultas Teknik, Fakultas Ilmu Keolahragaan, Fakultas Ilmu Sosial, Fakultas Ekonomi, Fakultas Pariwisata dan Perhotelan, dan Fakultas Matematika dan Ilmu Pengetahuan Alam. 


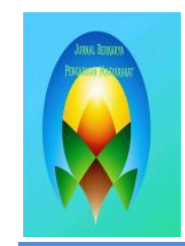

Journal Berkarya

Pengabdian kepada Masyarakat Vol. 2, No. 1, Mei, 2020, E-ISSN $\underline{\underline{2686}-6218}$

Dalam kegitan berlangsung tim massage dan dosen pembimbing juga mengggunakan tanda pengenal dan seragam, tidak hanya itu juga memberikan kesan menarik dengan adanya banner atau spanduk yang disediakan agar setiap tamu yang datang tertarik untuk merasakan pelayanan yang diberikan dan beberapa pengetahuan lainnya terkait dengan kesehatan. Tidak hanya itu juga disediakan kotak untuk pengumpulan aksi sosial untuk bencana tsunami di Palu, sehingga tamu yang datang bisa menyalurkan bantuannya kepada masyarakat yang tedampak. Pelayanan dilakukan sesuai dengan kebutuhan dari tamu atau pasien yang datang ikut berpartisipasi dalam sport massage.

Sebelum mendapatkan jasa pelayanan, para tamu diminta untuk mengisi buku tamu yang telah disediakan. Selain itu para tamu juga bisa untuk berbincang-bincaang dengan tim mengenai hal-hal yang berkaitan dengan massage. Dengan kata lain, adanya stand sport massage dapat menjadi ajang untuk berbagi ilmu. Tidak hanya sebatas orang-orang yang berasal dari Universitas Negeri Padang saja, tetapi semua orang yang ikut serta dalam kegiatan Dies Natalis tersebut,baik itu yang berasal dari Universitas Negeri Padang maupun yang berasal dari luar Universitas Negeri Padang.

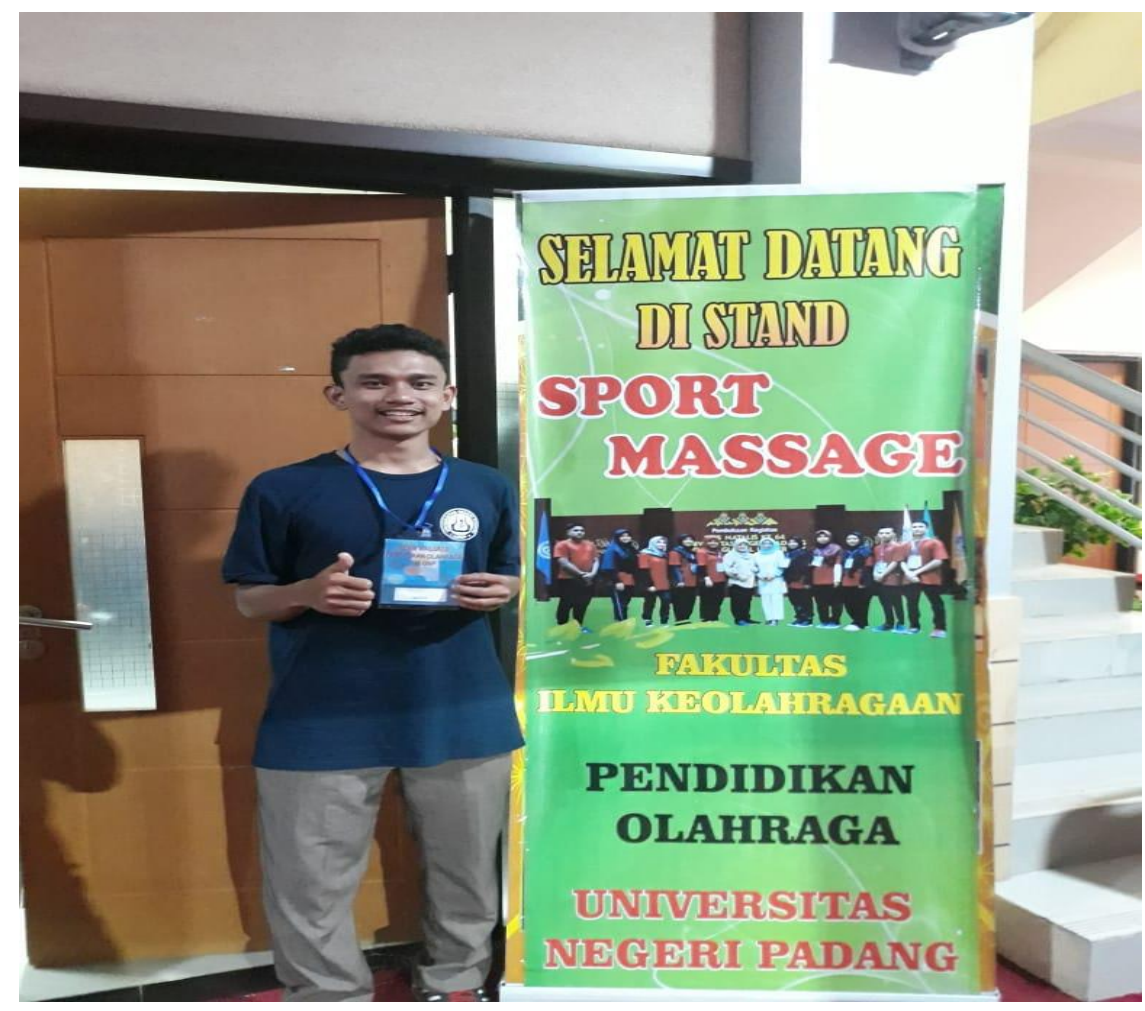

Gambar 1

Salah satu tim massage yang berdiri dengan barner stand sport massage 


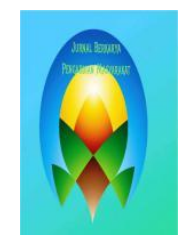

Journal Berkarya

Pengabdian kepada Masyarakat

Vol. 2, No. 1, Mei, 2020,

E-ISSN 2686-6218

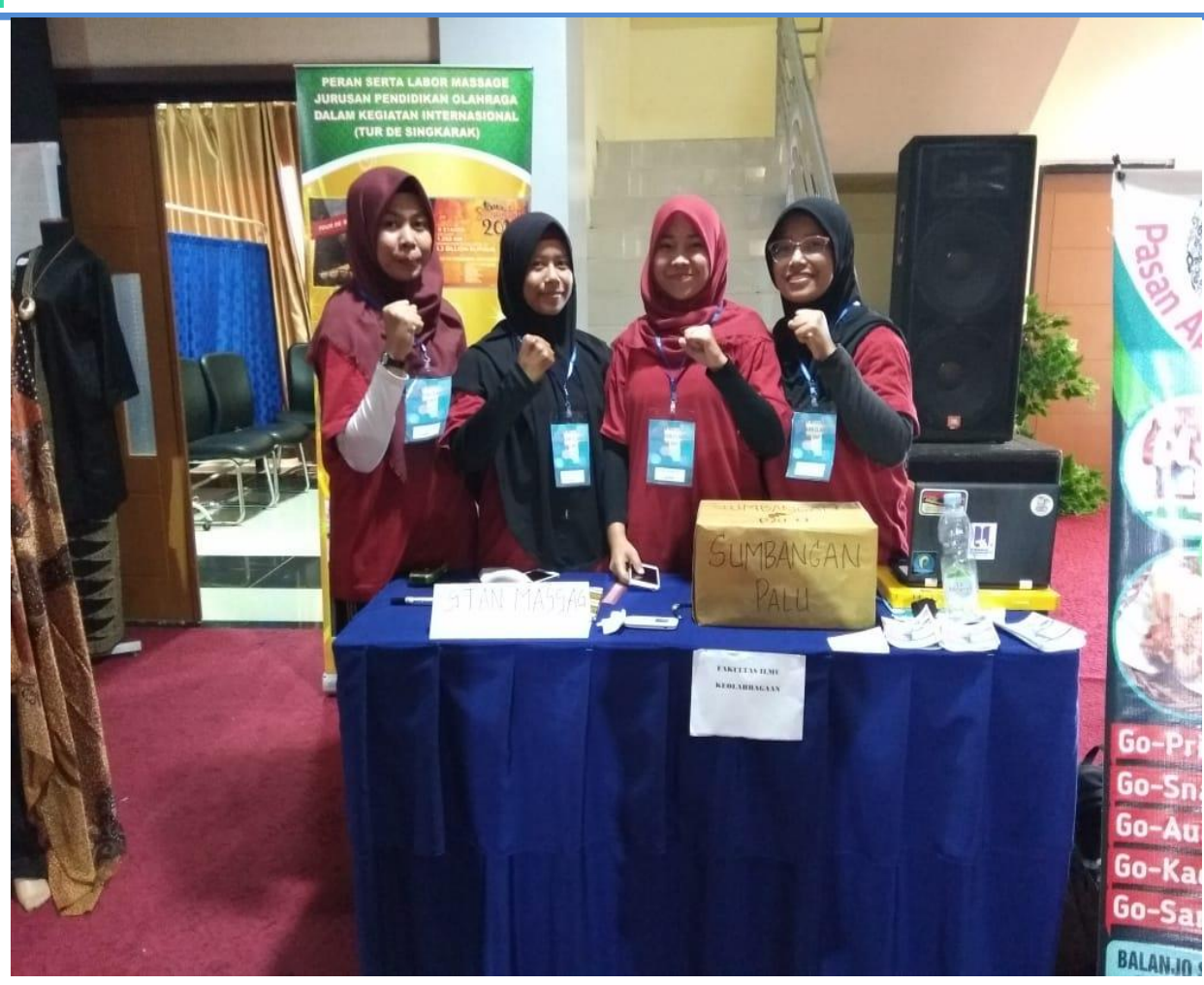

Gambar 2

Meja administrasi dan kotak sumbangan yang disediakan

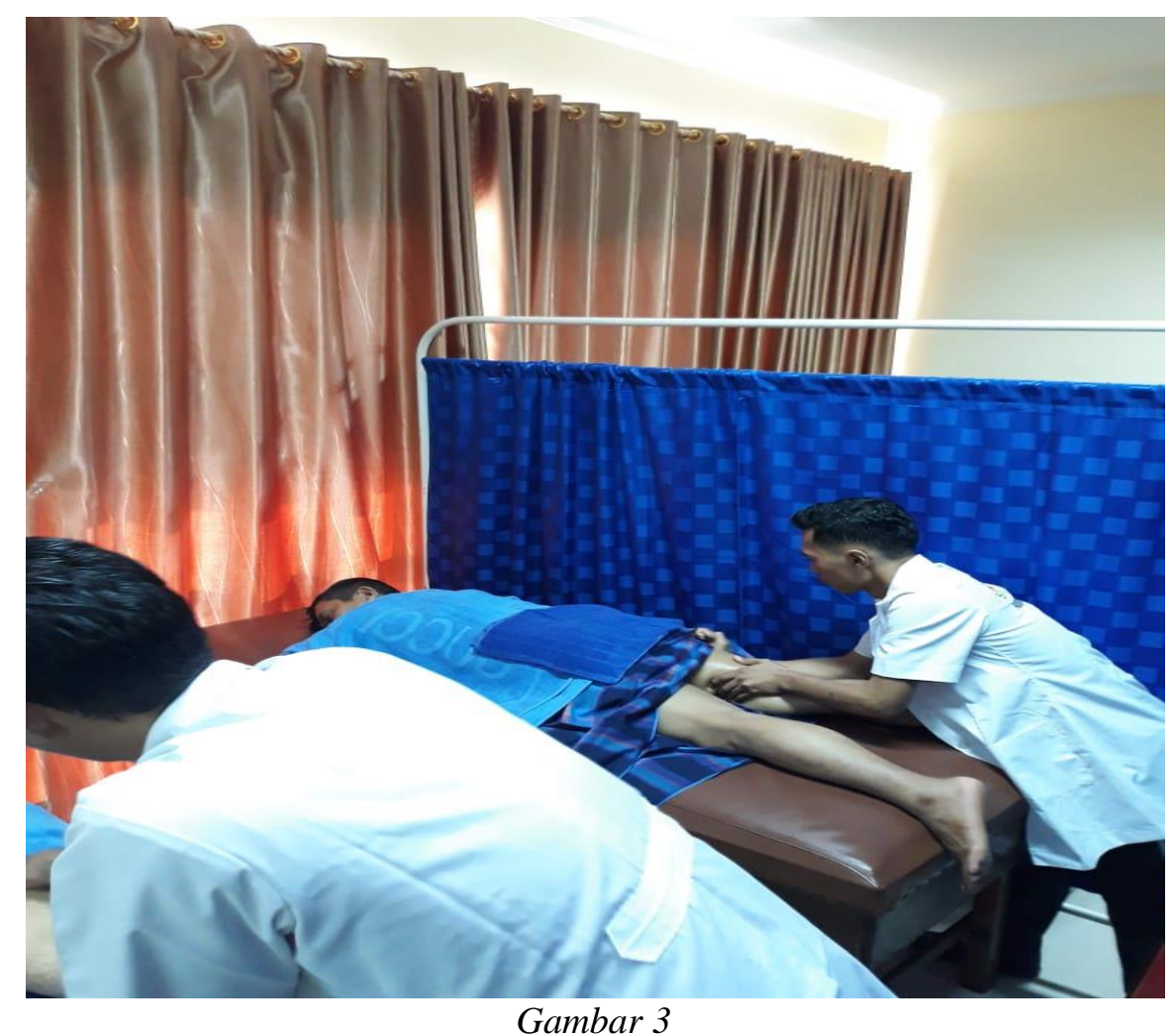

Bentuk Pelayanan sport massage 


\section{HASIL DAN PEMBAHASAN}

\section{Potensi sport massage}

Sport massage adalah kegitan olah tubuh yang bisa menyegarkan kembali tubuh seperti semula. Oleh karena itu pada kegiatan ini tim massge bekerjasama dengan dosen pembimbing mencoba memperkenakan dari sport massage dan sekaligus berpotensi membuka bahkan menyalurkan ulur tangan dari tamu yang datang dalam kegiatan dies natalis Universitas Negeri Padang ke 64 tahun.

Oleh karena itu, banyak dari tamu yang datang bisa merasakan bahkan meminta kembali untuk merasakan pelayanan sport massage yang diberikan oleh tim massage FIK yang sangat bermanfaat yang dirasakan bagi setiap tamu dies natalis. Dapat dikatakan bahwasanya jika tim serta sara dan prasaran sport massage ini dikembangkan dengan baik, maka akan membuka selebar-lebarnya lapangan kerja mahasiswa dan bahkan akan mendatang income baik untuk mahasiswa, dosen-dosen pembina massage dan Universitas Negeri Padang nantinya.

\section{Sarana Prasarana}

Sarana yang digunakan dalam kegitan dies natalis tempat tidur, alat minyak, handbody, handuk, bantal, dan tirai pembatas. Serta prasaran yang sudah disediakan oleh pihak panitia yakni, gedung, ruangan tertutup dan fasilitas yang mendukung lainnya. Adapun salah satu gambar sarana yang digunakan :

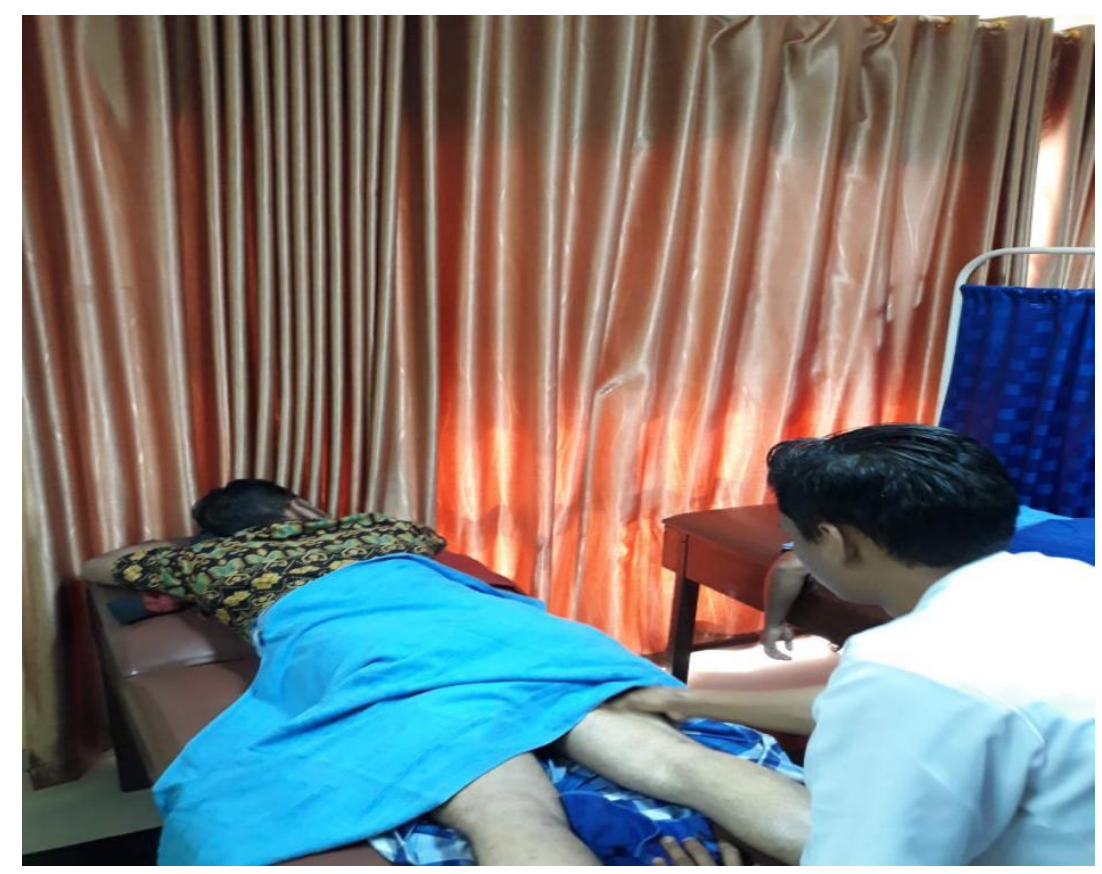

Gambar 4

Sarana dan prasana yang digunakan dalam memberikan pelayanan sport massage 
Pada masa sekarang, untuk memberikan jasa ataupun pelayanan, sangat tergantung dari sarana dan prasarana yang ada. Semakin lengkap sarana dan prasaran yang dimiliki oleh sebuah tempat jasa /pelayanan akan menambah nilai jual serta ketertarikan orang-orang untuk menggunakan jasa/layanannya. Tidak terkecuali untuk pemberian jasa/pelayanan sport massage. Sarana dan prasarana yang nyaman akan membuat orang-orang yang menggunakan jasa pelayanan sport massage semakin nyaman pula, tidak akan memnimbulkan efek risih atau tidak enak, karena sarana dan prasarana yang tersedia sudah sesuai dengan standarisasinya.

\section{Peningkatan Daya Tarik}

Sport massage berkembang sudah sangat lama dan kebanyakkan dikenal oleh olahragawan saja yang hanya bernaung dibawah olahraga. Pada saat dies natalis ini bisa lebih memperkenalkan sport massage dan sekaligus bisa menyalurkan bantuan kepada saudara yang terdampak bencana tsunami. Untuk meningkatkan daya tarik para tamu atau pengunjung bisa dengan pemberian warna stan dan tulisan-tulisan yang diberikan serta penawaran langsung kepada tamu yang turut hadir dalam dies natalis.

Kebanyakan masyarakat tertarik dengan relaksi yang bisa menyegarkan tubuh, melalui sport massage para pasien yang merasakan akan merasakan penyegaran tubuh kembali dan bisa menygarkan otak kembali. Oleh karena itu, tim massage melakukan pengenalan terhadap massage dengan menungkatannpengetahuan masyarakat agar lebih tertarik menggunakannya dibandingkan menggunakan obat kimia dan mengajak masyarakat untuk mengulurkan tangan kepada yang lebih membutuhkan. Yang terlibat dalam kegiatan ini adalah para tim massage yang berasal dari mahasiswa FIK dan dosen pembimbing dari dosen FIK. Berikut foto bersama tim massage dan dosen pembimbing.

Untuk itu dengan dilaksanakannya kegaiatan pengabdian masyarakat di kegiatan dies natalis UNP, yang dilengkapi dengan stand-stand yang baik dan bagus, serta pelayanan yang diberikan sangat ramah dan nyaman, akan memberikan dampak yang posistif. Para tamu dan masyarakat akan tertarik dan penasaran dengan pelayanan sport massage yang akan diberikan. Dari hasil kegiatan ini, masyarakat dan para tamu yang telah mencoba menggunakan jasa/pelayanan sport massage ini, semakin merasa tertarik dan ketagihan dengan apa yang mereka rasakan pada tubuh mereka. Rata-rata tim massage yang terlibat dalam kegiatan pengabdian ini, para tamu dan masyarakat memintak no kontak mereka untuk bisa dihubungi dan memberikan pelayanan/jasa sport massage lagi. 


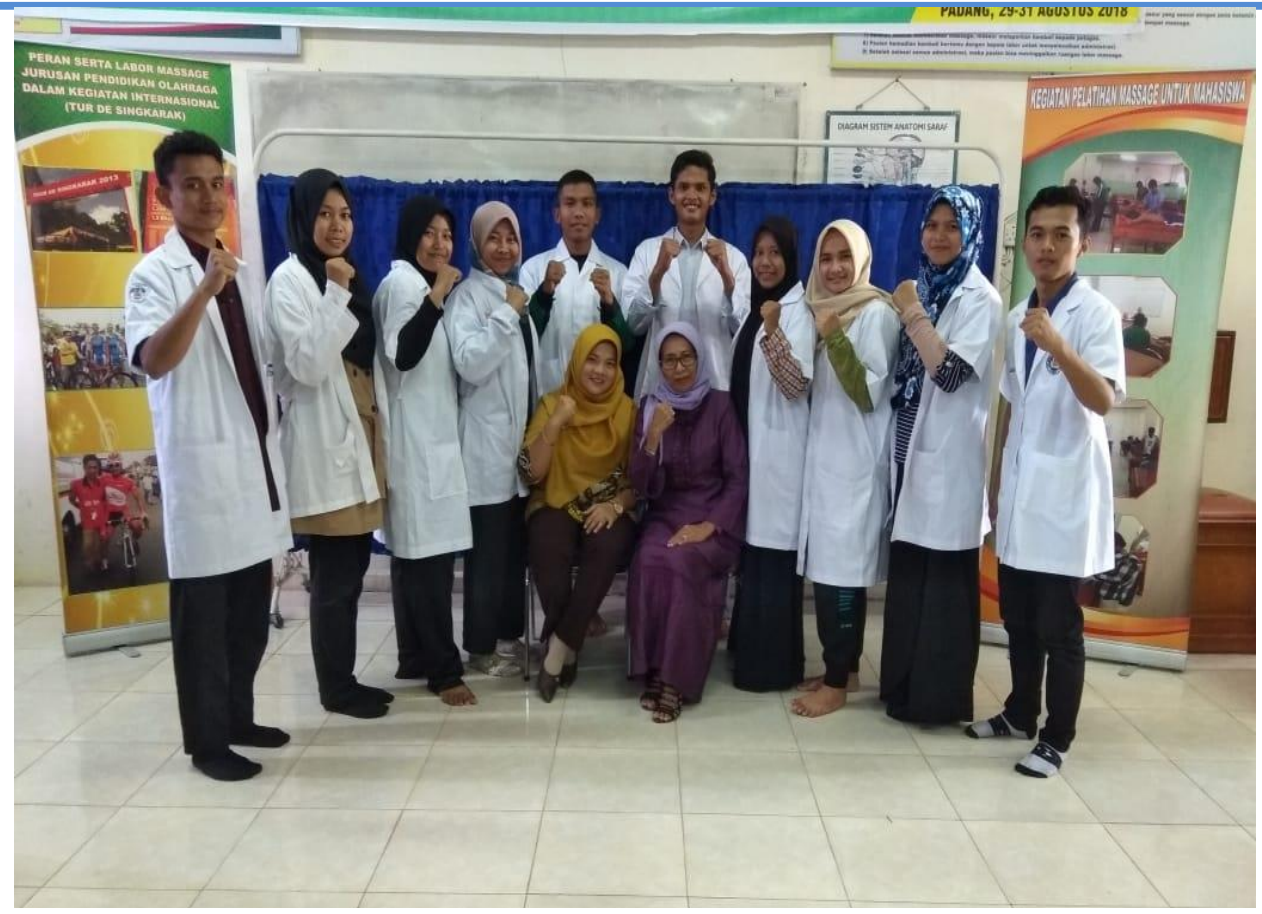

Gambar 5

Tim massage dan dosen pembimbing stand sport massage

\section{KESIMPULAN}

Sport massage belum banyak diketahui oleh masyarakat sebelumnya, namun sekarang dengan adanya dies natalis yang diadakan masyarakat bisa mendapatkan betapa pentingnya menjaga kesehatan dengan salah satunya melalui sport massage. Melalui kegiatan yang dilakukan banyak dari kalangan yang ikut serta bisa merasakan bagaimana relaksasi yang diberikan dan tubuh mejadi bugar kembali. Banyak yang meminta untuk penyegaran kembali dilakukan oleh tim massage dengan melalukan sport massage. Melalui kepuasan tersebut banyak tamu yang berminat untuk mendukung aksi sosial melalui kegiatan sport massage yang berupa materi. Jadi dapat disimpulkan bahwa masyarakat bisa mengenal dan mengetahui sport massage melalui kegiatan dies natalis Universitas Negeri Padang yang ke 64 tahun dn juga bisa membantu korban dampak tsunami di Palu.

Terdapat beberapa saran yang dapat dijadikan bahan pertimbangan untuk lebih mengembangkan sport massage, yakni bisa diharapkan dengan pengabdian kepada masyarakat oleh tim massage dan dosen pembimbing ini bisa memperkenalkan sport massage kepada masyarakat dan sekaligus sebagai aksi sosial peduli kepada masyarakat yang terdampak bencana. Sehingga sport massage bisa menjadi alternatif pengobatan relaksasi dibandingkan obat-obatan kimia. 


\section{PENGAKUAN}

Dalam kesempatan yang berikan tim pengabdian mengucapkan puji syukur kepada Allah SWT yang telah memberikan kegiatan pengabdian ini berjalan dengan lancar. Kami juga berterima kasih kepada pihak-pihak yang terlibat yang telah banyak membatu dalam berjalannya kegiatan ini. Terima kasih kepada pimpinan dan staf Universitas Ngeri Padang yang telah memberikan kesempatan kepada kami untuk menyemarakkan dies natalis Universitas Negeri Padang yang ke 64 tahun. Terima kasih kepada tamu yang sudah turut dalam aksi sosial yang kami lakukan sekaligus memperkenalkan sport massage.

\section{DAFTAR PUSTAKA}

Asnaldi, A., \& Kibadra, K. (2019). Sosialisasi Program Latihan Motor Ablity Kepada Asisten Pelatih Dojo Lembaga Karate-Do Indonesia Se-Kecamatan Koto Tangah. Jurnal Berkarya Pengabdian Masyarakat, 1(1), 67-74. https://doi.org/10.24036/JBA.V1I1.33

Darni, D., \& Welis, W. (2018). Peningkatan Keterampilan MassageCedera Olahraga Guru Pendidikan Jasmani Olahraga dan Kesehatan di Kecamatan Padang Utara. JURNAL STAMINA, 1(1), 415-424.

Darni, D., Deswandi, D., Wildawelis, W., \& Sepriadi, S. (2018). LATIHAN KETERAMPILAN MASASE TERPADU BAGI SISWA PENGURUS OSIS UNTUK PENINGKATAN PELAYANAN UKS DI SMP NEGERI 8 PADANG. Abdimas Dewantara, 1(2), 45-55

Depdikbud. 2005. Kamus Besar Bahasa Indonesia. Jakarta: Balai Pustaka

Depdikbud, 1980/1981. Spor Massage. Jakarta, Direktorat Jenderal Olahraga dan Pemuda.

Darni, 2009. Massage Olahraga Dasar Teori dan Manipulasi. Wineka Media, Malang

Fisu, A. A., \& Marzaman, L. U. (2018). Pemetaan Partisipatif Kampung Pesisir Kelurahan Tallo Kota Makassar. To Maega| Jurnal Pengabdian Masyarakat, 1(1), 22-28.

https://www.facebook.com/arfakingmassage/.../pengertian-sport-massagesportmassage.../1220736087942392/ 